\title{
Article \\ Central Energy Storage System to Reduce the Harmful Effects of PV Systems under a High Penetration Scenario
}

\author{
Elso Rodríguez ${ }^{1}$, Nimrod Vázquez ${ }^{1, *} \mathbb{D}$, Jaime Arau ${ }^{2}\left(\mathbb{D}\right.$, Rene Osorio $^{3}$, Fernando Medina ${ }^{1}$ and \\ Claudia Hernández ${ }^{1}$
}

1 Department of Electronics Engineering, Tecnológico Nacional de México-Instituto Tecnológico de Celaya, Celaya 38010, Mexico; elso.rodriguez@itcelaya.edu.mx (E.R.); fernando.medina@itcelaya.edu.mx (F.M.); claudia.hernandez@itcelaya.edu.mx (C.H.)

2 Electronics Department, Tecnológico Nacional de México-CENIDET, Cuernavaca 62490, Mexico; jaime.ar@cenidet.tecnm.mx

3 Computer Science and Engineering Department, Universidad de Guadalajara, Ameca 46600, Mexico; rene.osorio@valles.udg.mx

* Correspondence: n.vazquez@ieee.org; Tel.: +52-461-6117575

Citation: Rodríguez, E.; Vázquez, N.; Arau, J.; Osorio, R.; Medina, F.; Hernández, C. Central Energy Storage System to Reduce the Harmful Effects of PV Systems under a High Penetration Scenario. Electronics 2021, 10, 2418. https:// doi.org/10.3390/electronics10192418

Academic Editor: J. C. Hernandez

Received: 7 September 2021

Accepted: 26 September 2021

Published: 3 October 2021

Publisher's Note: MDPI stays neutral with regard to jurisdictional claims in published maps and institutional affiliations.

Copyright: (c) 2021 by the authors. Licensee MDPI, Basel, Switzerland. This article is an open access article distributed under the terms and conditions of the Creative Commons Attribution (CC BY) license (https:// creativecommons.org/licenses/by/ $4.0 /)$.

\begin{abstract}
Photovoltaic (PV) systems are used to generate electricity and they are considered less aggressive in their environmental impact. These systems require no further maintenance once they are installed, they do not pollute the environment and their average lifespan is high. These are the reasons why they are considered a good alternative for electricity generation. However, PV systems have different challenges to solve when they are connected to low voltage distribution grids and one of them is related to the power quality when there is a high penetration of PV systems, when voltage variations usually appear. In this paper, a central energy storage system (ESS) is considered to alleviate grid voltage variations under a high penetration scenario of PV systems instead of using multiples ESS. The proposal controls the energy injected into the grid to maintain the voltage variation within the standard, no limitations are imposed on the PV systems, and then as an advantage of the proposal, the PVs' available energy is fully delivered to the grid. In addition, in the absence of sunlight the ESS may provide power to the grid. An analysis and experimental setup were built to validate the proposed scheme.
\end{abstract}

Keywords: energy storage system (ESS); high PV penetration; PV systems

\section{Introduction}

Nowadays, the harmful effects on the environment from using fossil fuels for electricity generation are evident causing serious air and water pollution, and their overuse has been associated with global warming with severe consequences [1-4]. Governments have been taking several actions to reduce the use of these fuels, including the development of new technologies for electricity generation, such as photovoltaic (PV) systems [5,6]. However, the massive use of these systems presents new challenges and problems that must be addressed and solved to make these technologies as efficient and effective as possible [7-11]. In the literature, different works show that the massive connection of PV systems to the grid has several undesirable effects [12], and a summary of these consequences is presented here.

The large-scale use of PV systems and their massive connections to distribution systems can lead to several problems, therefore, different technologies to mitigate these effects have been developed [13]. They can be grouped into two categories depending on which aspect of the systems they are related to. The first category relates to the gridside control, which includes solutions such as using cables with a higher cross-section to reduce their impedance [14] and the use of on-line tap changers (OLTCs) [15]; however, these methods, despite being efficient, are expensive and require modifying the facilities 
of the distribution grid. On the other hand, the second group relates to consumer-side solutions encompassing control over the PV systems [16], which would include direct control over their shutdown in the event of overvoltage [17], a reactive power injection from the PV system [18,19], and also the use of energy storage systems (ESS) to absorb the energy generated by the PV systems [20]. These methods can be implemented as integrated systems into the grid without the need for facilities modifications.

Several authors have shown that the use of energy storage systems (ESS) is one of the best alternatives for mitigating the negative effects of high penetration [20-24], because no changes are required in the distribution lines, they can be considered even after the PV system has already been installed and can be added to the system independently of the user.

Different works have been reported on in the literature to mitigate the voltage variation from using an ESS. In [25], the authors suggest using an OLTC in conjunction with ESS to minimize the harmful effects of high penetration, and the system is controlled based on network behavior statistics. The ESS is installed near the OLTC, which is not the best location according to the sensitivity analysis made in this work. In [15], the authors use a coordinated control between the residence and the ESS with distribution transformers, which become complex since multiple communications links are required. In [22], the authors present an ESS for each residence and a battery charging strategy to manage their capacity of the ESS, but the system is only able to handle a single PV system. In [26], a strategy to improve the stages of battery charging and discharging is presented, but no emphasis on the grid power quality is made.

Other strategies address the control of the power delivered by photovoltaic systems [27-29]. Some of them consider the use of active and reactive power, but these strategies do not take full advantage of the generation capacity of the photovoltaic systems, wasting energy and decreasing the PV panel's lifetime.

In this paper, a central ESS is suggested to alleviate the harmful effects of the high penetration of PV systems in a residential cluster case. The proposed system permits the storing of energy but also injects it into the grid in such a way that helps to alleviate the voltage variations in the grid. The central ESS is located in a fixed position but this permits it to compensate for the whole residential cluster under a high PV penetration scenario; for this, a sensitivity analysis was performed. This proposal controls the energy injected to or demanded by the grid to regulate the grid voltage, and the ESS size was reduced by allowing a voltage variation between the voltage standard limits, eliminating the MPPT limitations of having no storage solutions, which avoids wasting the PV energy. In Figure 1, a diagram of the proposed system is depicted.

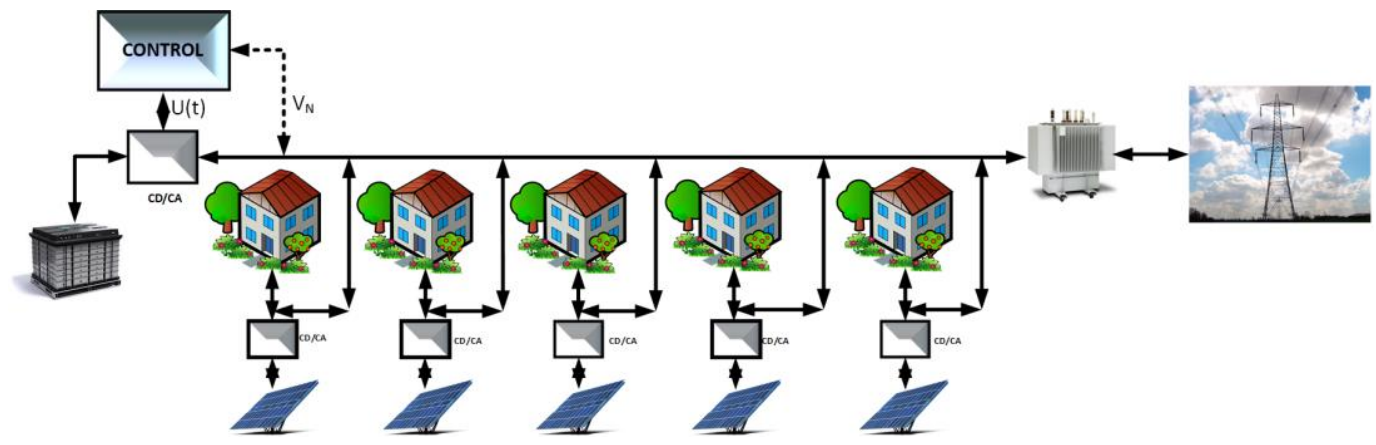

Figure 1. Proposed system.

This paper is organized as follows: in section two the system under study is analyzed and a sensitivity analysis is performed; in section three the proposed approach is addressed; in section four the experimental results are shown; and finally, the discussion and conclusions are presented. 


\section{Low Voltage Distribution System under a High PV Penetration Scenario}

\subsection{High PV Penetration Scenario}

Several publications show how grid voltage profiles are affected by the massive connection of PV systems. In [30], the authors show that the existing voltage in the house " $n-1$ " presents a deviation that depends on the value of the injected current into the grid and on the cable impedance. The voltage variation is determined by [30]:

$$
\Delta V=I_{n} * Z_{n},
$$

where $\Delta V$ is the deviation in voltage level in the house $n-1, I_{n}$ is the current injected from bus $n$, and $Z_{n}$ is the line impedance between the $(n-1)$ th and $n$-th PV households.

The equation that determines the voltage deviation along the feeder considering the resistance and impedance of the line is [30]:

$$
\Delta V=\frac{R \bullet P_{g_{-} n}+X Q_{g_{-} n}}{\left|V_{g_{-} n}\right|}+j \frac{X \bullet P_{g_{-} n}-R \bullet Q_{g_{-} n}}{\left|V_{g_{-} n}\right|},
$$

where $R$ is the feeder resistance, $X$ is the feeder reactance, $V_{g_{-} n}$ is the transformer distribution voltage, $P_{g_{-} n}$ is the $\mathrm{n} P V$ real power, and $Q_{g_{-} n}$ is the $\mathrm{n} P V$ reactive power.

They also conclude that because in the distribution lines the $R / X$ ratio is generally high, the power of the grid significantly affects the absolute voltage values in the PCC.

In [31], a case study of a simulation is presented, showing the results of how the voltage profile in a distribution grid suffers severe voltage elevations when a PV penetration of up to $75 \%$ occurs.

\subsection{Low Voltage Distribution System}

A low voltage distribution system is considered in this work, in a residential cluster in which ten residences inject their PV energy into the grid. For simplicity, it was assumed that all residences inject the same current into the grid (represented by the current source) and that the impedance between them had the same value, while the distribution transformer was represented by a voltage source $\left(V_{G}\right)$, as shown in Figure 2 .

This approach allowed us to obtain the formula to calculate the voltage present at each node as:

$$
V_{N}=V_{G}+Z I_{P} \sum_{i=N \max -N+1}^{N \max } i
$$

where $V_{N}$ is the node voltage, $V_{G}$ is the grid voltage, $Z$ is the impedance between residences, $I_{P}$ is the current injected by each residence, and $N_{\max }$ is the number of residences.

The analysis showed that the node that is farthest from the distribution transformer would have a higher voltage. If a power-consuming element were connected, the current injected into the grid would decrease and, in the same way, the voltages present at the nodes would also decrease. Figure 3 shows this case.

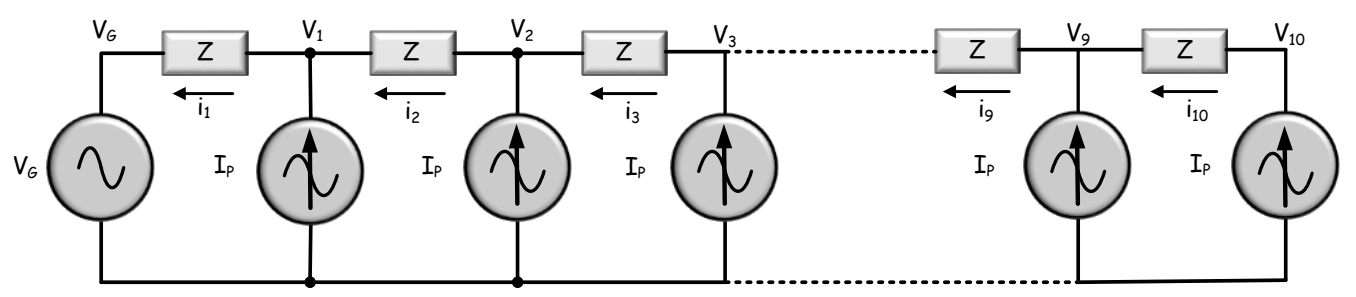

Figure 2. Equivalent circuit of a massive connection of photovoltaic systems. 


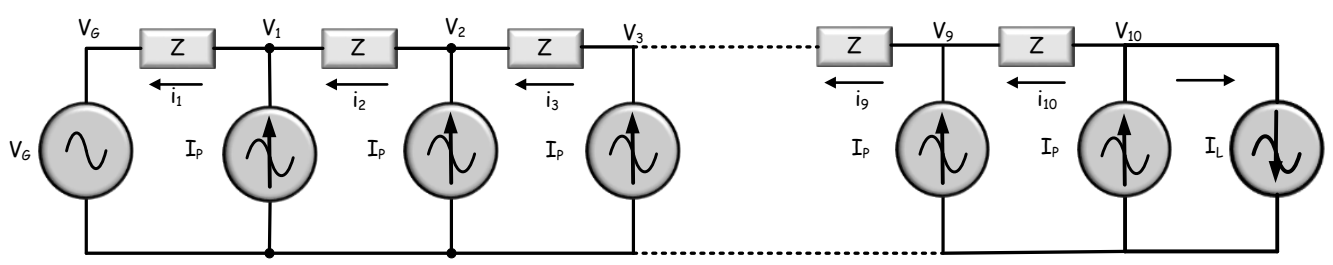

Figure 3. Equivalent circuit of a massive connection of photovoltaic systems with the powerconsumer.

Analyzing the system illustrated in Figure 3, the following equation was obtained:

$$
V_{N}=V_{G}+Z\left(I_{P} \sum_{i=N \max -N+1}^{N \max } i-M I_{L}\right)
$$

where $M$ is the node in which the power-consuming element is allocated, and $I_{L}$ is the absorbed current by the power-consuming element.

This equation demonstrates that, by connecting an element that consumes the power injected into the grid by the photovoltaic systems, the harmful effects of high penetration can be cancelled out or at least alleviated. This element would be implemented with an ESS.

\subsection{Sensitivity Analysis}

In order to determine the best ESS allocation into the low voltage distribution grid, a sensitivity analysis was performed. Ten nodes were considered (representing the residences), and every node had a PV system; the resistances and inductances between the houses had values of $0.025 \Omega$ and $10 \mathrm{mH}$, respectively, considering average individual loads of $45 \Omega$; the PV systems were represented by current-dependent sources and delivered $960 \mathrm{~W}$ per house; grid voltage was $120 \mathrm{~V}_{\mathrm{RMS}}$ at $60 \mathrm{~Hz}$; and PSIM $^{\circledR}$ was the software used for the analysis.

Figure 4 shows each node voltage when the ESS was placed in all the different nodes, and the graph shows the behavior of node voltages (RMS value) as a function of the ESS allocation. The ESS was controlled to assure $120 \mathrm{~V}_{\text {RMS }}$ at the node that was placed, and as can be observed, the best allocation for the ESS was around node seven, since all the node voltages were low. If the ESS were connected further from the distribution transformer, a better position would be obtained when compared to a closer connection point.

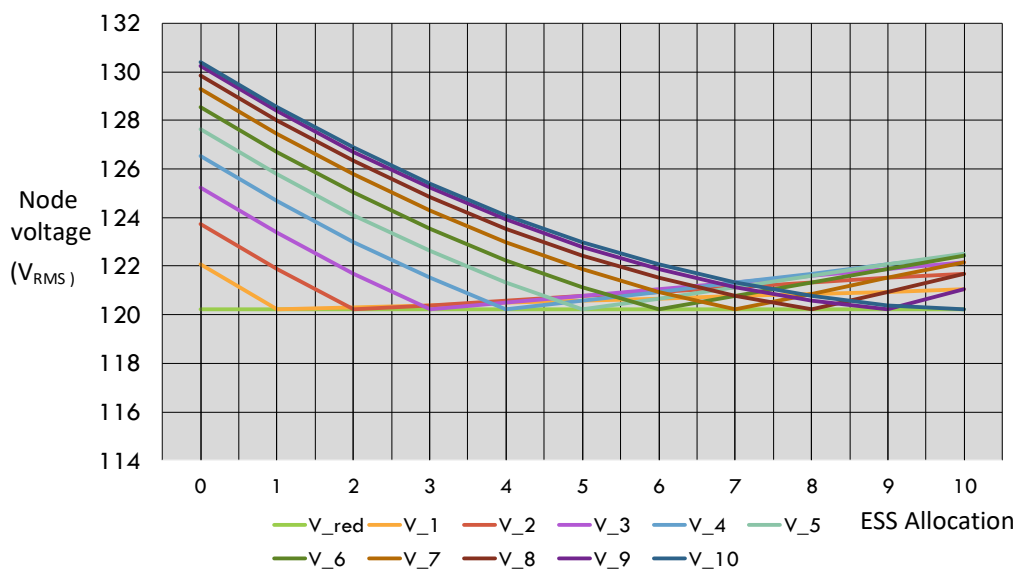

Figure 4. Node voltage ( $\left.\mathrm{V}_{\mathrm{RMS}}\right)$ vs. node ESS Allocation.

Figure 5 shows the evolution of the node voltage levels $\left(\mathrm{V}_{\mathrm{RMS}}\right)$ if the ESS regulates the node voltage at different levels but within the standard. This permits a reduction of 
the energy capacity required by the ESS. Figure 5a illustrates the voltage of the different nodes when the ESS is allocated in node seven and regulating the voltage at a different level within the standard. Figure $5 \mathrm{~b}$ shows the same but allocates the ESS on node eight, and so on for the other figures. As can be observed, position ten permits a lower voltage when the voltage of the node is regulated further from the nominal value.

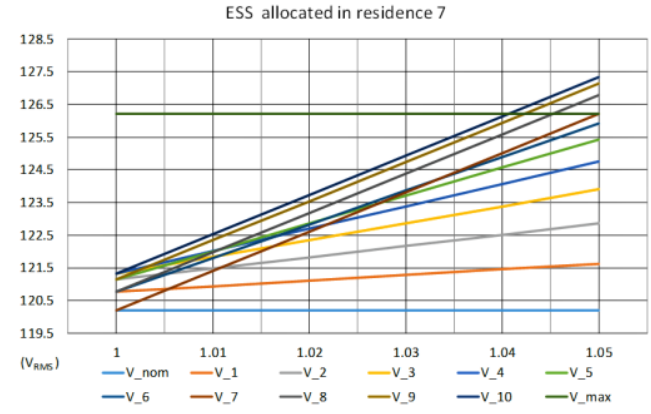

(a)

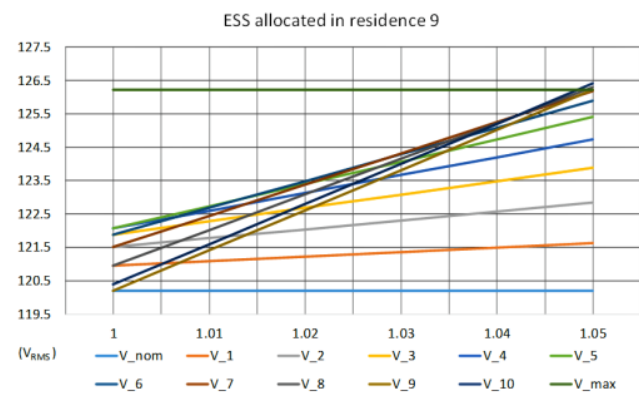

(c)

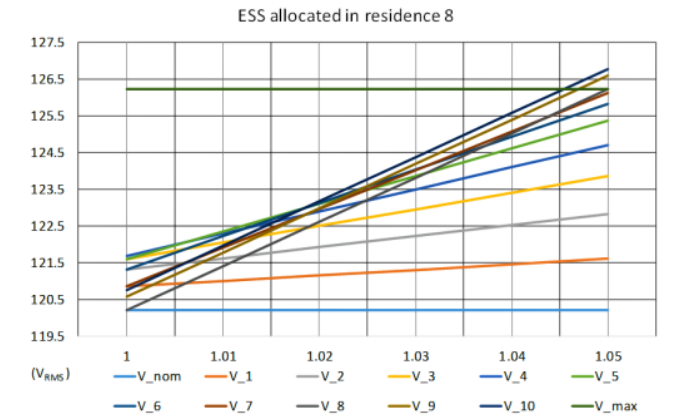

(b)

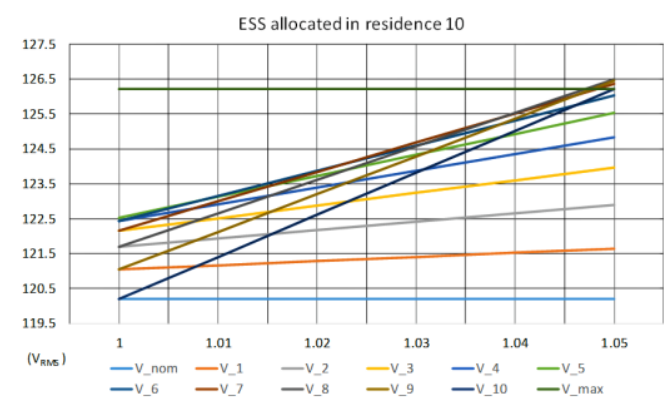

(d)

Figure 5. Node voltages ( $\mathrm{V}_{\mathrm{RMS}}$ ) under different regulating voltage levels. (a) ESS allocated in residence 7, (b) ESS allocated in residence 8, (c) ESS allocated in residence 9, and (d) ESS allocated in residence 10.

Figure 6 shows the current demanded by the ESS, when it is placed at nodes six to ten but regulating the voltage node at different levels. As can be observed, if the node is regulated close to the nominal value, the current demanded by the ESS will be higher and then also the storage capacity. When connecting the ESS to the farthest point and regulating the voltage at a higher level, the size and capacity of the ESS will be reduced as can be observed.

\section{Current absorbed by ESS}

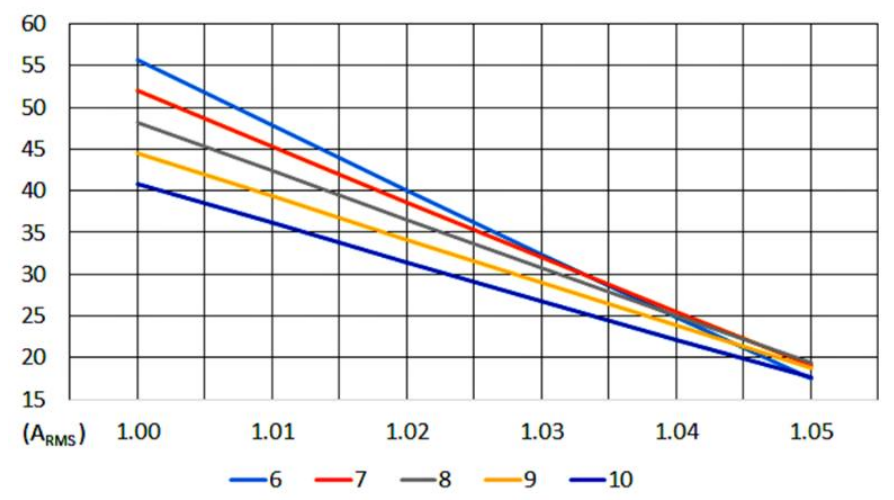

Figure 6. Currents demanded ( $\left.\mathrm{A}_{\mathrm{RMS}}\right)$ by ESS under different regulating voltage levels.

After the analysis, it was observed that in order to maintain the voltages within the standard while avoiding the requirement for a huge ESS, the system should be allocated in 
the last node and the node voltage regulated near to the standard limit (around $+4 \%$ of the nominal voltage).

\section{Proposed System}

\subsection{Power Stage and Controller}

Figure 7 shows a diagram of the proposed system, which should be allocated on the last node. The power stage consists of a single-phase inverter, grid filter $\left(\mathrm{L}_{1}\right)$, and ESS. The control stage consists of a high penetration controller (HPC), which determines the current reference for the current controller; a current controller based on a proportional-resonant compensator [32,33]; and a grid synchronization circuit based on a second-order integral system (SOGI-FLL).
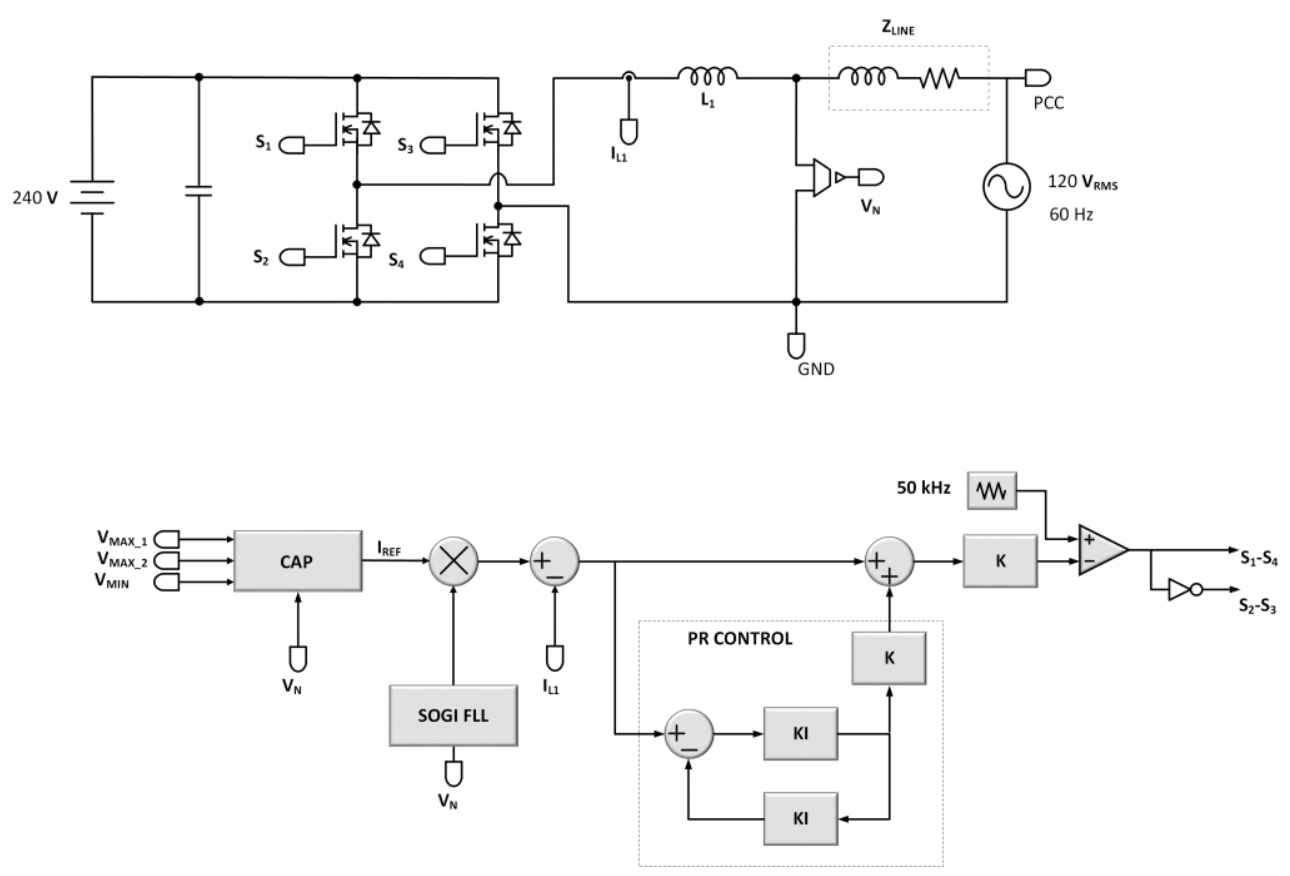

Figure 7. Proposed system.

\subsection{Operation Modes}

The system has three operating modes depending on the grid voltage level. During the highest solar radiation conditions, the panel is expected to generate more energy than the load consumes. In the case of the grid voltage level rising above the established limit, the surplus of energy will be directed to the ESS (first mode); on the contrary, if it does not rise above the established limit then the power does not need to be stored in the ESS (second mode). In the case of the voltage level dropping for an established magnitude, the ESS having enough stored power, and the daytime is between 20 and $24 \mathrm{~h}$, then the ESS will deliver its energy at a constant current (third mode).

Figure 8 shows the flow chart of the HPC. The controller monitors the node voltage where the ESS is allocated. First, the voltage is compared with a low-level condition to determine if the ESS should be used to deliver energy to the grid, considering the power of the battery and the time as previously discussed. If the voltage is high, then the current reference is increased periodically to demand energy from the grid until the voltage level reaches below the established limit; the setpoint will be decreased when the voltage reduces in value below the low limit established. 


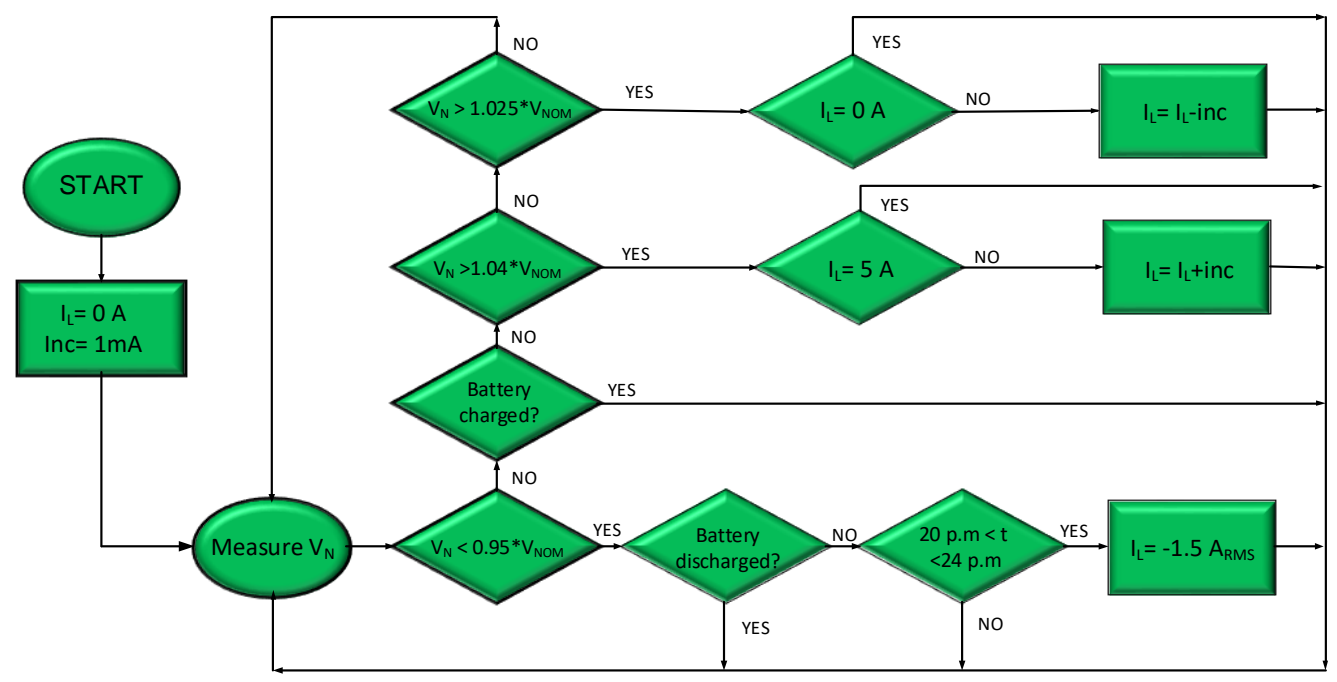

Figure 8. Flow diagram.

\section{Experimental Results}

In order to validate the proposed idea, a low-power prototype was implemented and different tests were carried out. Figure 9 shows the system connected to an equivalent system that represents the first residence's system and the grid (by using the equivalent Thevenin circuit). The resistance $R_{o}$ and $R_{D}$ are dummy loads to avoid damage at the voltage supplies employed when the system delivers energy to the source. An AC power supply was used to emulate the grid and a DC power supply for the ESS.

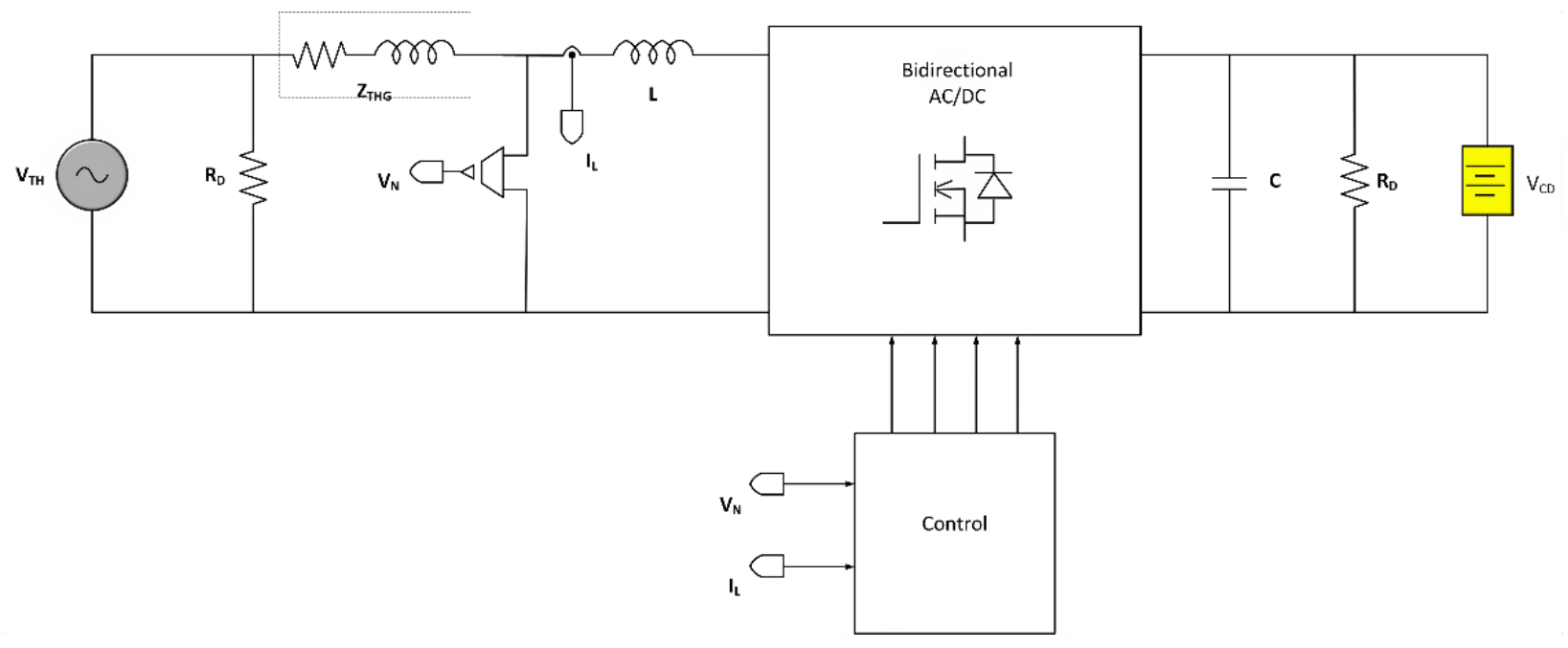

Figure 9. Connecting the system to the node.

The prototype specifications are illustrated in Table 1. 
Table 1. Specifications of the prototype.

\begin{tabular}{cc}
\hline Element & Value \\
\hline $\mathrm{L}$ & $1.6 \mathrm{mH}$ \\
$\mathrm{R}_{\mathrm{TH}}$ & $2.5 \Omega$ \\
$\mathrm{L}_{\mathrm{TH}}$ & $1 \mathrm{mH}$ \\
$\mathrm{C}$ & $940 \mu \mathrm{F}$ \\
$\mathrm{R}_{\mathrm{D}}$ & Dummy load \\
$\mathrm{V}_{\mathrm{CD}}$ & $240 \mathrm{~V}$ \\
$\mathrm{~V}_{\mathrm{TH}}$ & $113 \mathrm{~V}_{\mathrm{RMS}}-130 \mathrm{~V}_{\mathrm{RMS}} @ 60 \mathrm{~Hz}$ \\
MOSFETS & $\mathrm{C}_{\mathrm{M} 0160120 \mathrm{D}}$ \\
Switching frequency & $50 \mathrm{kHz}$ \\
\hline
\end{tabular}

Due to the proposed prototype being designed to operate at low power, the grid impedance was increased to be able to replicate the voltage increment on the node.

Thevenin's voltage was implemented with the voltage source Agilent 6812B. The control was fully implemented on the board NI MyRIO-1900, programmed with LabView software version 2015. Figure 10 shows a photograph of the developed prototype, and Figure 11, a photograph of the power supplies used.
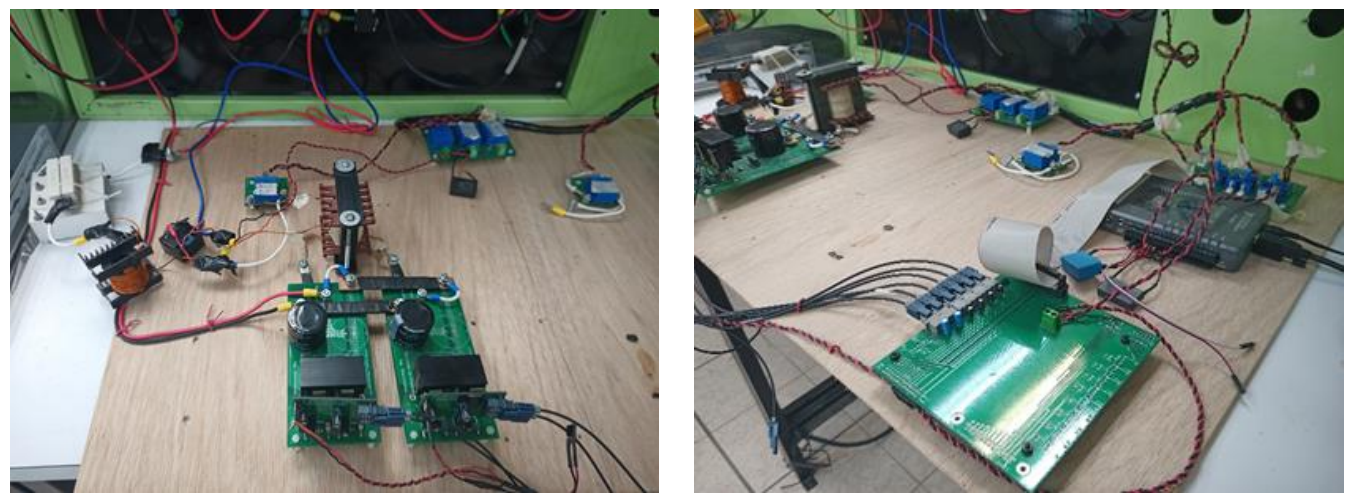

Figure 10. Prototype. Power (left) and control (right) stages.
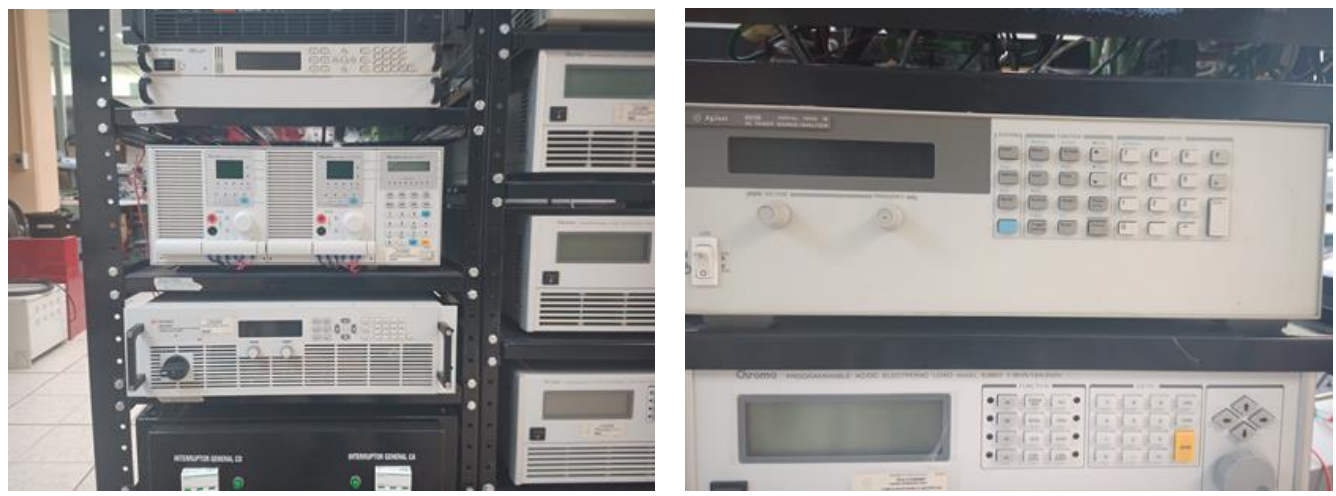

Figure 11. Power supplies used.

\subsection{Tests}

In order to evaluate the proposed system, different tests were designed. It was considered that there was a maximum irradiance without energy consumption and the nominal grid voltage was $120 \mathrm{~V}_{\text {RMS }}$. Ten residences with a maximum injected power of $1125 \mathrm{~W}$ were considered, therefore each residence would inject $0.937 \mathrm{~A}_{\mathrm{RMS}}$. According to 
Equation (4), the injection of that current into the grid would cause an increase in the last node voltage up to $132.88 \mathrm{~V}_{\mathrm{RMS}}$. Solving for $\mathrm{I}_{\mathrm{L}}$ gives:

$$
I_{B}=\frac{\sum_{i=N_{\max }-N+1}^{i=N_{\max }} i}{M} I_{P}-\frac{0.04}{Z M} V_{g},
$$

The ESS must absorb 3.23 A RMS to adjust the node voltage to $104 \%$ of the nominal voltage. According to the ANSI c84.1 standard, this value is within its allowed limits.

\subsubsection{Node Voltage Evolution When the PV Injects Energy}

Figure 12 illustrates the voltage increment when the PV injected current increases. If the current injected by each residence increased from $0.43 \mathrm{~A}_{\mathrm{RMS}}$ to $0.75 \mathrm{~A}_{\mathrm{RMS}}$, the voltage at the residence farthest from the transformer would increase to $130 \mathrm{~V}_{\mathrm{RMS}}$. In this case, the proposed system was turned off, and then the voltage at the node rose above the standard limits.

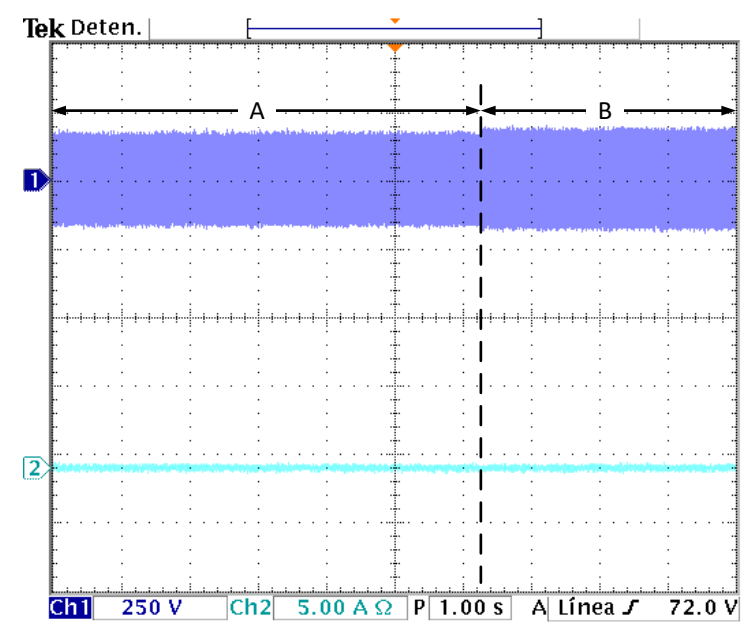

Figure 12. Node voltage increment due to PV injected current increment in the system, which turned off the system. A: $V_{N}=120 V_{\text {RMS }}$ and $B: V_{N}=130 V_{R M S}$. From top to bottom: node voltage and injected current.

Figure 13 shows the node voltage when the proposed system was enabled. The system was at the last condition given in the previous test, and then suddenly the system was turned on. It was observed that the current absorbed by the system increased up to $3 \mathrm{~A}_{\mathrm{RMS}}$, and the node voltage dropped to a value within the standard limit.

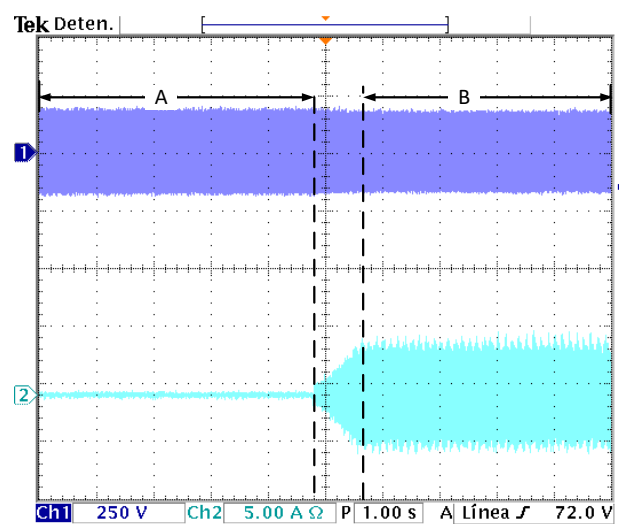

Figure 13. Voltage transition when the system was turned on. A: $V_{N}=130 V_{R M S}$ and $B$ : $\mathrm{V}_{\mathrm{N}}=124.6 \mathrm{~V}_{\mathrm{RMS}}$. From top to bottom: node voltage and injected current. 
Figure 14 shows a more complex test. The system started with the system at a nominal voltage value of $120 \mathrm{~V}_{\mathrm{RMS}}$, therefore the system did not demand current. The following scenario presents a voltage increment due to a PV current injection, but in this case, the system was on. The system response can be observed that when the voltage was incremented, the system reduced its value by demanding current to the grid. A gradual increase in the current drawn by the system can be seen until the node voltage dropped to an established level (from $130 \mathrm{~V}_{\mathrm{RMS}}$ to $124.6 \mathrm{~V}_{\mathrm{RMS}}$ ), then suddenly the PV current injected into the grid decreased, the node voltage of the residence dropped and the system continued to absorb current, although it decreased its consumption. Finally, when the current injected into the grid decreased to zero, the node voltage dropped to $120 \mathrm{~V}_{\mathrm{RMS}}$, so the system stopped absorbing current.

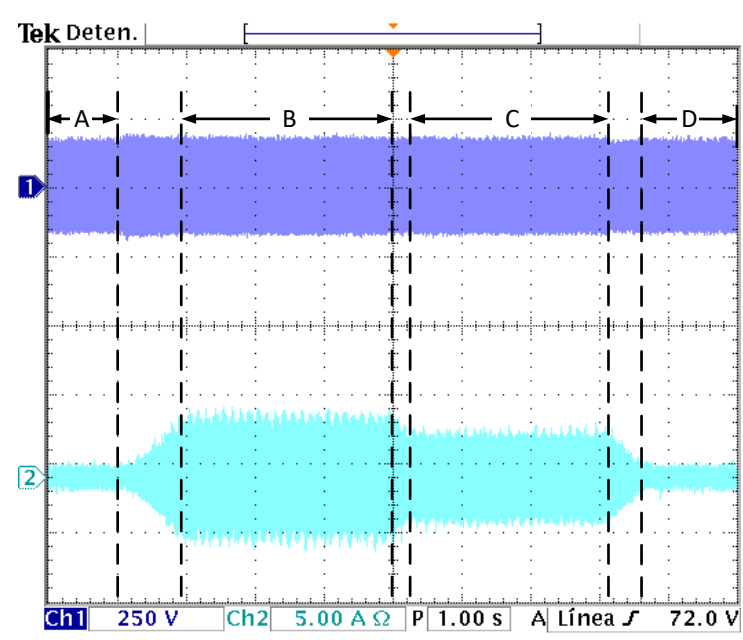

(a)

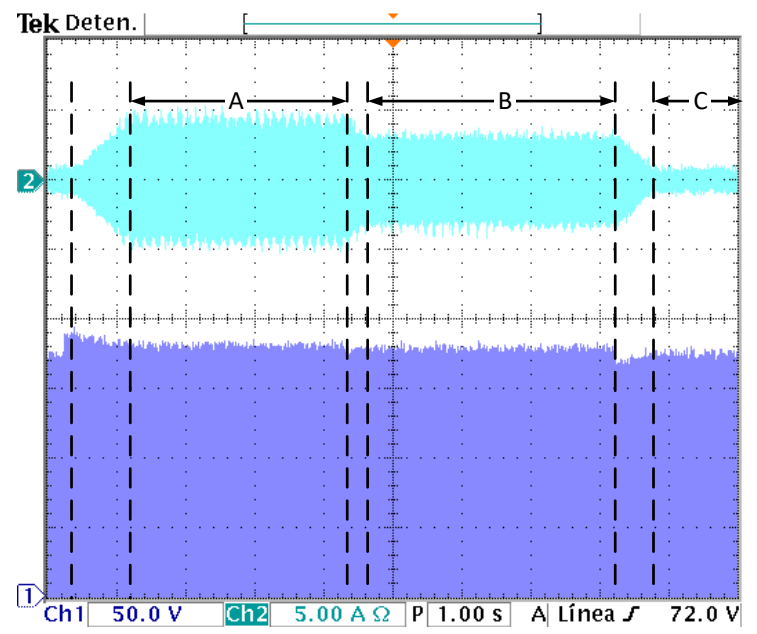

(b)

Figure 14. Node voltage variations with the proposed system turned on. $A: V_{N}=120 V_{R M S}, B: V_{N}=124.6 V_{R M S}$, $\mathrm{C}: \mathrm{V}_{\mathrm{N}}=124.6 \mathrm{~V}_{\mathrm{RMS}}$ and $\mathrm{D}: \mathrm{V}_{\mathrm{N}}=120 \mathrm{~V}_{\mathrm{RMS}}$. (a) original waveform and (b) magnified waveforms.

\subsubsection{Steady-State Waveforms When the PV Injects Energy}

Figure 15 shows the steady-state waveforms when the ESS is absorbing energy. The THD of the current is $2.6 \%$ and the PF is 0.98 as is shown in Figure 16.

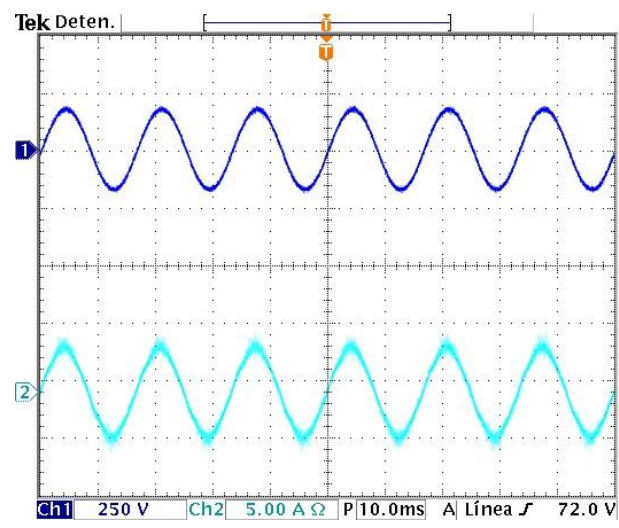

Figure 15. Steady-state waveforms when the PV injects energy. From top to bottom: node voltage and injected current. 

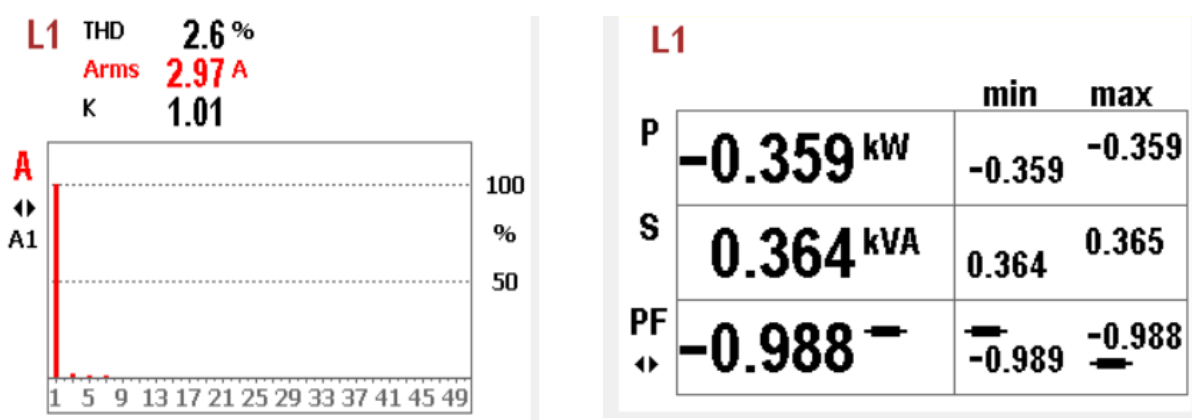

Figure 16. Measured THD and harmonic spectra, and PF when the PV injects energy.

\subsubsection{Node Voltage Evolution When the ESS Is Discharged}

During the night, the ESS delivers current to the grid when the PV does not inject energy and the residences are consuming energy, in this case, the voltage is lower than the nominal value. Under these conditions, the proposed system would inject current into the grid, raising the voltage. This scenario is shown in Figure 17, starting the system at the given time.

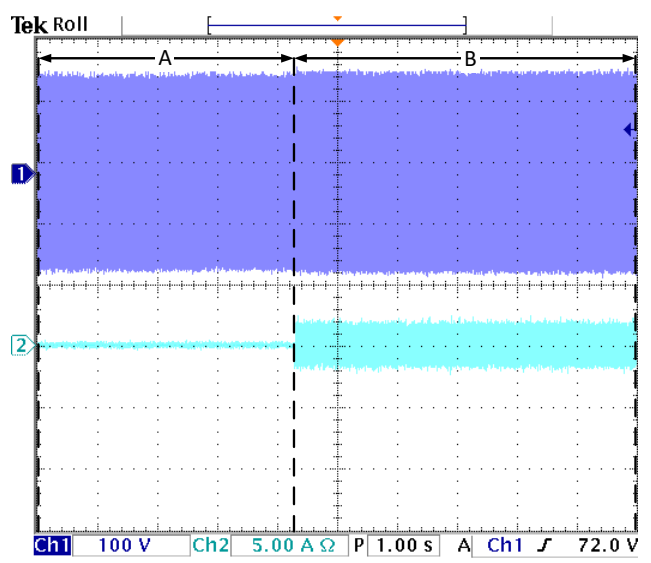

Figure 17. System injecting current. $A: V_{N}=113 V_{R M S}$ and $B: V_{N}=114.6 V_{R M S}$.

\subsubsection{Steady-State Waveforms When the ESS Is Discharged}

Figure 18 shows the waveform of the proposed system at a steady-state when the current is injected into the grid. Figure 19 shows the THD and value of the current when the system injects current into the grid.



Figure 18. Voltage grid and current injected waveforms when the ESS is discharged. 



Figure 19. Measured THD and harmonic spectra, and PF when the ESS is discharged.

\section{Discussion}

The benefits of using PV systems to generate electricity are evident and among them is the reduction in the use of fossil fuels, which allows a reduction in the emission of polluting gases. However, there are harmful effects of voltage variations that the extensive use of this technology brings with it. These can be alleviated by connecting the elements that consume the energy injected into the grid, which in this case was a central ESS.

From the obtained results, it can be deduced that connecting an ESS to the grid in the last residence to absorb the energy, is a good alternative to keeping the voltage levels within the standard limits, but certainly, a sensitivity analysis should be conducted to determine the best location depending on the grid conditions.

A central ESS is proposed in this work that demands energy only when the voltage reaches the standard limits, thus, reducing the ESS capacity and cost. The system maintains the voltage level within tolerance by injecting current into the grid. At night the system returns this energy to the grid. The system had an adequate response to the different transitions that were performed, and the system reduced the grid/node voltage rise when necessary.

Table 2 shows a comparison between the power consumed by the proposed system and the power consumed if the voltage levels were maintained the nominal value and the suggested operating voltage.

Table 2. Comparison between different voltage regulation strategies.

\begin{tabular}{ccccc}
\hline System & Voltage & Fixed Voltage & Absorbed Current & Power Consumed \\
\hline Typical & $130 \mathrm{~V}_{\mathrm{RMS}}$ & $120 \mathrm{~V}_{\mathrm{RMS}}$ & $4.12 \mathrm{~A}_{\mathrm{RMS}}$ & $494 \mathrm{~W}$ \\
Proposed & $130 \mathrm{~V}_{\mathrm{RMS}}$ & $124.6 \mathrm{~V}_{\mathrm{RMS}}$ & $2.3 \mathrm{~A}_{\mathrm{RMS}}$ & $286 \mathrm{~W}$ \\
\hline
\end{tabular}

Another benefit of using an ESS in the proposed scheme is that it can be connected to the grid without modifying the facilities or the PV operation, therefore, they can be used in both old and new installations, and the PV panels can track the maximum power point permitting its optimized use.

Table 3 shows a comparison of the different strategies used to alleviate the harmful effects of high penetration. In [25], a battery-transformer system was used. It was based on the statistics of the behavior of the grid. Transformer taps were set by a schedule. In the same way, the ESS absorbed energy from the grid according to a schedule. If the use of these strategies was not enough to diminish the voltage, then the photovoltaic systems would curtail the power generated. The use of a transformer did not correct for voltage variations at the furthest points. The use of a communication bus increased the risk of failure. There was excessive use of ESS. 
Table 3. Techniques to alleviate the damaging effects of a high penetration of PV systems.

\begin{tabular}{|c|c|c|c|c|}
\hline Reference & Advantages & Disadvantages & Complexity & Cost/Economics \\
\hline$[15,25]$ OLTC and ESS. & $\begin{array}{l}\text { Due to the use of three } \\
\text { methods, the reliability } \\
\text { and speed of response } \\
\text { increases. }\end{array}$ & $\begin{array}{l}\text { They are based on the } \\
\text { generation of statistics } \\
\text { and do not consider } \\
\text { random cases. } \\
\text { Continuous use of } \\
\text { batteries in case of } \\
\text { excessive power } \\
\text { generation. They } \\
\text { require a control bus. } \\
\text { There are power losses } \\
\text { due to the use of } \\
\text { transformers. }\end{array}$ & $\begin{array}{l}\text { High. By employing } \\
\text { three methods, the } \\
\text { complexity of the } \\
\text { system increases and } \\
\text { thus also the risk of } \\
\text { failure. }\end{array}$ & Medium. \\
\hline $\begin{array}{c}\text { [22] ESS with } \\
\text { decentralized control. }\end{array}$ & $\begin{array}{l}\text { They consider the } \\
\text { capacity of the batteries } \\
\text { and protect their } \\
\text { lifespan. }\end{array}$ & $\begin{array}{l}\text { They use an extensive } \\
\text { control bus. In addition, } \\
\text { their use of batteries } \\
\text { can be excessive. One } \\
\text { system per residence. }\end{array}$ & $\begin{array}{l}\text { High. It is necessary to } \\
\text { use a control bus. }\end{array}$ & $\begin{array}{l}\text { High. It requires a } \\
\text { communication and } \\
\text { control bus. }\end{array}$ \\
\hline $\begin{array}{l}\text { [34] Active power } \\
\text { curtailment. }\end{array}$ & $\begin{array}{l}\text { It can be implemented } \\
\text { in the control of PV } \\
\text { systems. }\end{array}$ & $\begin{array}{l}\text { The full capacity of the } \\
\text { PV systems is wasted. } \\
\text { Energy is wasted. The } \\
\text { useful life of the PV } \\
\text { systems is reduced. }\end{array}$ & $\begin{array}{l}\text { Low. The control can be } \\
\text { included in the inverter } \\
\text { control of the PV } \\
\text { system. }\end{array}$ & $\begin{array}{c}\text { Cheap. No extra } \\
\text { equipment is required. }\end{array}$ \\
\hline $\begin{array}{l}\text { [14] Rebuilding the } \\
\text { grid. }\end{array}$ & $\begin{array}{l}\text { No control or extra } \\
\text { equipment is necessary. }\end{array}$ & $\begin{array}{c}\text { Unless it is a new grid } \\
\text { installation, it requires } \\
\text { a complete grid } \\
\text { rebuild. }\end{array}$ & High. & High. \\
\hline $\begin{array}{l}{[35,36] \text { Capacitive-type }} \\
\text { reactive power. }\end{array}$ & $\begin{array}{l}\text { Simple installation. No } \\
\text { modifications to the } \\
\text { electrical grid are } \\
\text { required. }\end{array}$ & $\begin{array}{l}\text { There is no precise } \\
\text { control of the reactive } \\
\text { power injected into the } \\
\text { grid. May cause } \\
\text { voltage rise or fall } \\
\text { outside of standard. }\end{array}$ & Low. & Medium. \\
\hline
\end{tabular}

Simple installation. Portable. Battery life care. Consideration of

Proposed system. the dimensions of the battery. No modifications to the electrical grid are required.
The best position of the ESS should be determined before Low. Medium. installation.

In [15], the authors also used an ESS and a solid-state OLTC to regulate voltage levels. They proposed a coordinated control of the distributed ESS with tap changer transformers for voltage rise mitigation. The centralized control determined the operation of the ESS. Transformer stress and switching cycles were reduced. However, there was excessive use of the ESS, which would increase the size and cost.

In [22], the authors suggested the use of a decentralized control and the use of an ESS for each photovoltaic system. They presented a strategy for managing the battery charging process that reduces overuse. By managing the process of charging the batteries, they extended the life of the batteries; however, the employ of multiple ESS increased the volume and cost of the system.

Reducing the power generated by the systems is one of the easiest and cheapest methods to implement [34]. However, in the long term, it is not a good alternative due to 
the premature damage to photovoltaic systems and energy waste. This work does not take full advantage of the capacity of the photovoltaic systems.

Replacing the grid cables with larger diameter ones (rebuilding) is a functional alternative because it reduces the impedance of the lines [14]. However, it is expensive and requires a total grid modification. In the installation of new grids it may be suitable. It is a more expensive and different alternative to the proposal presented in this paper.

The use of capacitors to inject reactive power is another alternative that is easy to implement; however, it is difficult to control the amount of reactive power supplied, which can cause under- or over-voltage [35,36].

Therefore, this proposal represents a good alternative to reduce the harmful effects of PV systems under high penetration scenarios.

\section{Conclusions}

In the absence of PV systems, the levels of the supply voltages in the houses connected to the grid which are further away from the distribution transformer have significant drops, up to $4.5 \%$ of the nominal value of the grid voltage.

When there is a massive connection of PV systems to the distribution lines there are voltage surges, especially in houses farther from the distribution transformer, up to $11 \%$ higher than the voltage standard limits.

These effects can be alleviated by connecting the elements that consume the energy injected into the grid, and specifically, ESS are proposed in this work. A central ESS is proposed with the system located in a place that permits it to compensate for all the nodes in the grid, but where the ESS capacity is reduced by regulating the voltage at a point near to the standard upper limit. A low power prototype was implemented that permitted evaluating the performance of the proposal, which showed good results for alleviating the voltage variations caused by the PV systems under a high penetration scenario.

Author Contributions: Conceptualization, N.V. and C.H.; methodology, J.A. and R.O.; validation, E.R. and F.M.; resources, C.H.; supervision, N.V. and J.A. All authors have read and agreed to the published version of the manuscript.

Funding: This research was supported by “Tecnológico Nacional de México", grant number 13133.21-P.

Conflicts of Interest: The authors declare no conflict of interest.

\section{Nomenclature}

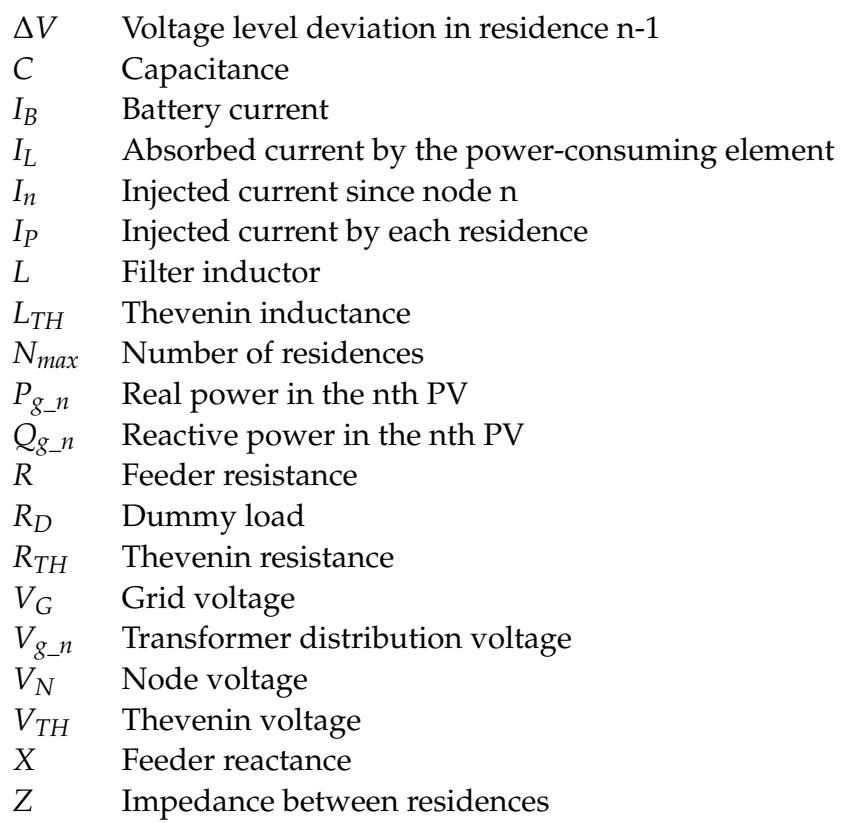




\section{References}

1. Kong, F.; Dong, C.; Liu, X.; Zeng, H. Quantity versus quality: Optimal harvesting wind power for the smart grid. Proc. IEEE 2014, 102, 1762-1776. [CrossRef]

2. The International Energy Agency. Available online: http://www.iea.org/statistics/electricity (accessed on 15 August 2019).

3. Manickavasagam, K.; Thotakanama, N.K.; Puttaraj, V. Intelligent energy management system for renewable energy driven ship. IET Electr. Syst. Transp. 2018, 9, 24-34. [CrossRef]

4. Tian, X.; Zhao, R.; Wang, J. The Multi-Levels Modeling to Green Manufacturing Energy System Using Multi-Agent Energy Hub. In Proceedings of the IEEE 8th Joint International Information Technology and Artificial Intelligence Conference (ITAIC), Chongqing, China, 24-26 May 2019; pp. 1884-1888.

5. Rashid, K. Design, Economics, and Real-Time Optimization of a Solar/Natural GAS hybrid Power Plant. Doctoral Dissertation, The University of Utah, Salt Lake City, UT, USA, 2019.

6. Algarin, C.R.; Álvarez, O.R. Un panorama de las energías renovables en el Mundo, Latinoamérica y Colombia. Espacios 2018, $39,10$.

7. Celli, G.; Natale, N.; Pilo, F.; Pisano, G.; Bignucolo, F.; Coppo, M.; Cerretti, A.G. Containment of power losses in LV networks with high penetration of distributed generation. CIRED-Open Access Proc. J. 2017, 2017, 2183-2187. [CrossRef]

8. Vilman, A.; Jerele, M. Voltage quality provision in low-voltage networks with high penetration of renewable production. CIRED-Open Access Proc. J. 2017, 2017, 2053-2056. [CrossRef]

9. Chidurala, A.; Saha, T.K.; Mithulananthan, N. Harmonic impact of high penetration photovoltaic system on unbalanced distribution networks-learning from an urban photovoltaic network. IET Renew. Power Gener. 2016, 10, 485-494. [CrossRef]

10. Kim, Y.S.; Kim, E.S.; Moon, S.I. Frequency and voltage control strategy of standalone microgrids with high penetration of intermittent renewable generation systems. IEEE Trans. Power Syst. 2015, 31, 718-728. [CrossRef]

11. Islam, M.; Mithulananthan, N.; Hossain, J.; Shah, R. Dynamic voltage stability of unbalanced distribution system with high penetration of single-phase PV units. J. Eng. 2019, 2019, 4074-4080. [CrossRef]

12. Walling, R.A.; Saint, R.; Dugan, R.C.; Burke, J.; Kojovic, L.A. Summary of distributed resources impact on power delivery systems. IEEE Trans. Power Deliv. 2008, 23, 1636-1644. [CrossRef]

13. Rashid, K.; Safdarnejad, S.M.; Powell, K.M. Dynamic simulation, control, and performance evaluation of a synergistic solar and natural gas hybrid power plant. Energy Convers. Manag. 2019, 179, 270-285. [CrossRef]

14. Shayani, R.A.; de Oliveira, M.A.G. Photovoltaic generation penetration limits in radial distribution systems. IEEE Trans. Power Syst. 2011, 26, 1625-1631. [CrossRef]

15. Liu, X.; Aichhorn, A.; Liu, L.; Li, H. Coordinated control of distributed energy storage system with tap changer transformers for voltage rise mitigation under high photovoltaic penetration. IEEE Trans. Smart Grid 2012, 3, 897-906. [CrossRef]

16. Chamana, M.; Chowdhury, B.H.; Jahanbakhsh, F. Distributed control of voltage regulating devices in the presence of high PV penetration to mitigate ramp-rate issues. IEEE Trans. Smart Grid 2016, 9, 1086-1095. [CrossRef]

17. Gagrica, O.; Nguyen, P.H.; Kling, W.L.; Uhl, T. Microinverter curtailment strategy for increasing photovoltaic penetration in lowvoltage networks. IEEE Trans. Sustain. Energy 2015, 6, 369-379. [CrossRef]

18. Turitsyn, K.; Sulc, P.; Backhaus, S.; Chertkov, M. Options for control of reactive power by distributed photovoltaic generators. Proc. IEEE 2011, 99, 1063-1073. [CrossRef]

19. Hashemi, M.; Agelidis, V. Evaluation of voltage regulation mitigation methods due to high penetration of PV generation in residential areas. In Proceedings of the 2013 International Conference on Renewable Energy Research and Applications (ICRERA), Madrid, Spain, 20-23 October 2013; pp. 1180-1189.

20. Lu, X.; Wang, J. A game changer: Electrifying remote communities by using isolated microgrids. IEEE Electrif. Mag. 2017, 5, 56-63. [CrossRef]

21. Zeraati, M.; Golshan, M.E.H.; Guerrero, J.M. Distributed control of battery energy storage systems for voltage regulation in distribution networks with high PV penetration. IEEE Trans. Smart Grid 2016, 9, 3582-3593. [CrossRef]

22. Marra, F.; Yang, G.; Træholt, C.; Østergaard, J.; Larsen, E. A decentralized storage strategy for residential feeders with photovoltaics. IEEE Trans. Smart Grid 2013, 5, 974-981. [CrossRef]

23. Von Appen, J.; Stetz, T.; Braun, M.; Schmiegel, A. Local voltage control strategies for PV storage systems in distribution grids. IEEE Trans. Smart Grid 2014, 5, 1002-1009. [CrossRef]

24. Kabir, M.N.; Mishra, Y.; Ledwich, G.; Dong, Z.Y.; Wong, K.P. Coordinated control of grid-connected photovoltaic reactive power and battery energy storage systems to improve the voltage profile of a residential distribution feeder. IEEE Trans. Ind. Inform. 2014, 10, 967-977. [CrossRef]

25. Yang, H.T.; Chen, Y.T.; Liao, J.T.; Yang, C.T. Over-voltage mitigation control strategies for distribution system with high PV penetration. In Proceedings of the 18th International Conference on Intelligent System Application to Power Systems (ISAP), Porto, Portugal, 11-16 September 2015; pp. 1-6.

26. Alam, M.J.E.; Muttaqi, K.M.; Sutanto, D. Mitigation of rooftop solar PV impacts and evening peak support by managing available capacity of distributed energy storage systems. IEEE Trans. Power Syst. 2013, 28, 3874-3884. [CrossRef]

27. Riquelme-Dominguez, J.M.; Martinez, S. A Photovoltaic Power Curtailment Method for Operation on Both Sides of the PowerVoltage Curve. Energies 2020, 13, 3906. [CrossRef] 
28. Carvalho, P.M.S.; Correia, P.F.; Ferreira, L.A.F.M. Distributed Reactive Power Generation Control for Voltage Rise Mitigation in Distribution Networks. IEEE Trans. Power Syst. 2008, 23, 766-772. [CrossRef]

29. Medina, F.; Vazquez, N.; Vaquero, J.; Arau, J.; Estrada, L.; Rodriguez, E. Active Power Management for PV Systems under High Penetration Scenario. Int. J. Photoenergy 2021, 2021, 9940862. [CrossRef]

30. Hu, J.; Li, Z.; Zhu, J.; Guerrero, J.M. Voltage stabilization: A critical step toward high photovoltaic penetration. IEEE Ind. Electron. Mag. 2019, 13, 17-30. [CrossRef]

31. Tonkoski, R.; Turcotte, D.; El-Fouly, T.H. Impact of high PV penetration on voltage profiles in residential neighborhoods. IEEE Trans. Sustain. Energy 2012, 3, 518-527. [CrossRef]

32. Shen, G.; Zhu, X.; Zhang, J.; Xu, D. A new feedback method for PR current control of LCL-filter-based grid-connected inverter. IEEE Trans. Ind. Electron. 2010, 57, 2033-2041. [CrossRef]

33. Teodorescu, R.; Blaabjerg, F.; Borup, U.; Liserre, M. A new control structure for grid-connected LCL PV inverters with zero steady-state error and selective harmonic compensation. In Proceedings of the 19th Annual IEEE Applied Power Electronics Conference and Exposition, Anaheim, CA, USA, 22-26 February 2004; pp. 580-586.

34. Tonkoski, R.; Lopes, L.A.C.; El-Fouly, T.H.M. Coordinated Active Power Curtailment of Grid Connected PV Inverters for Overvoltage Prevention. IEEE Trans. Sustain. Energy 2011, 2, 139-147. [CrossRef]

35. Vinnal, T.; Janson, K.; Kalda, H.; Kutt, L. Analyses of supply voltage quality, power consumption and losses affected by shunt capacitors for power factor correction. In Proceedings of the 2010 Electric Power Quality and Supply Reliability Conference, Kuressaare, Estonia, 16-18 June 2010; pp. 53-60.

36. Téllez, A.Á.; López, G.; Isaac, I.; González, J.W. Optimal reactive power compensation in electrical distribution systems with distributed resources. Review. Heliyon 2018, 4, e00746. [CrossRef] [PubMed] 